\title{
A CRISE DA DEMOCRACIA REPRESENTATIVA E A NECESSIDADE DE CONCILIAÇÃO DO CRESCIMENTO ECONÔMICO COM O DESENVOLVIMENTO HUMANO
}

\section{THE CRISIS OF REPRESENTATIVE DEMOCRACY AND THE NEED FOR RECONCLILIATION OF ECONOMIC GROWTH WITH HUMAN DEVELOPMENT}

\author{
${ }^{1}$ Ana Araújo Ximenes Teixeira Mendes
}

\section{RESUMO}

O presente artigo analisa a crise da democracia como reflexo da necessidade de conciliação do crescimento econômico com o desenvolvimento humano. Inicialmente, aborda a relação entre as mudanças que transformaram o capitalismo democrático em supercapitalismo, e o enfraquecimento dos modelos de democracia representativa. Posteriormente, sob a ótica da Teoria da Democracia, verifica que a democracia representativa pressupõe a preservação de um patamar econômico e social mínimo para todos os cidadãos. Ao final, conclui-se que a compatibilização entre crescimento econômico e desenvolvimento humano é imprescindível para a superação da crise da democracia.

PALAVRAS-CHAVE: Teoria da Democracia; Direitos Políticos; Desenvolvimento humano; Direitos Sociais; Supercapitalismo.

\begin{abstract}
This article analyzes the crisis of democracy as a reflection of the need to reconcile economic growth with human development. Initially, it addresses the relationship between the changes that transformed democratic capitalism into supercapitalism, and the weakening of representative democracy models. Subsequently, from the point of view of the Theory of Democracy, it finds that representative democracy presupposes the preservation of a minimum economic and social level for all citizens. In the end, it is concluded that the compatibility between economic growth and human development is essential for overcoming the crisis of democracy.
\end{abstract}

KEYWORDS: Theory of democracy; Political Rights; Human development; Social Rights; Supercapitalism.

\footnotetext{
${ }^{1}$ Doutoranda em Direito Constitucional pelo Programa de Pós-Graduação em Direito da Universidade de Fortaleza - UNIFOR, Ceará, CE, (Brasil). Mestre em Direito Constitucional pela Faculdade de Direito da Universidade Federal do Ceará - UFC, Ceará, CE, (Brasil). E-mail: anaxmendes@ icloud.com.
} 


\section{INTRODUÇÃO}

As manifestações no Brasil em julho de 2013, o Occupy Wall Street, o Movimento dos Indignados (na Espanha e em Portugal), as mobilizações de 2012 do movimento estudantil chileno são reflexos mundiais da crise da democracia. Grupos e organizações reunidos através de redes sociais e que não constituem partidos políticos ou movimentos sociais propriamente ditos estão cada dia mais ocupando espaço na sociedade e buscando introduzir novas formas de participação política que sejam eficazes e acessíveis aos cidadãos comuns.

Alguns desses agrupamentos deram azo à formação de partidos políticos com práticas e modelo organizacional inovadores, como o Movimento dos Indignados da Espanha, que gerou o partido Podemos, com organização horizontal e proibição de contribuições que não sejam de pessoas físicas. A versão portuguesa dos Indignados deu origem ao partido Bloco de Esquerda e contribuiu para a chegada ao poder do primeiro-ministro Antônio Costa, após décadas de domínio conservador do parlamento português, como uma reação à recessiva política de austeridade econômica preconizada pelo Fundo Monetário Internacional e outros organismos financeiros mundiais.

Seguindo essa tendência, o partido grego Syriza tem origem semelhante e compromisso expresso com o resgate da democracia e o combate à parcela da agenda do capitalismo financeiro que precariza o trabalho e as condições de vida da população. Embora haja nuances diferenciadoras nas pautas de reivindicação, modo de agir e origem é um denominador comum entre essas coletividades a bandeira da reconstrução da democracia. Mesmo num país referencial para o moderno conceito de democracia como os Estados Unidos, ao longo das últimas décadas a confiança dos cidadãos na capacidade do governo de atuar em benefício da maioria do povo decresceu expressivamente.

Dentre os muitos fatores que levaram a democracia moderna à difícil situação em que se encontra, os históricos devem introduzir o debate, tendo em vista o benefício em termos de compreensão dos demais elementos que a contextualização histórica fornece. Assim, deve ser ressaltado que, entre os anos de 1945 e 1975, tanto nos Estados Unidos quanto na Europa ocidental, a Guerra Fria estimulava os governos democráticos a promoverem políticas públicas para melhoria da qualidade de vida dos trabalhadores, 
impulsionando outrossim a elaboração de acordos e obtenção de concessões por parte do mercado, num esforço destinado a evitar o surgimento de condições econômicas e sociais favoráveis à derrota do bloco capitalismo.

Porém, após trinta anos de paz artificial entre democracia e capitalismo, a ressurreição do liberalismo econômico liderada por Margaret Thatcher e Ronald Reagan, respectivamente no Reino Unido e nos EUA, aliada à integração mundial dos mercados conhecida como globalização e às inovações tecnológicas que reduziram postos de trabalho solaparam progressivamente os direitos sociais nas democracias ocidentais, ao mesmo tempo que, com o fim da Guerra Fria, desapareceu o elemento histórico que impulsionava os governos democráticos a proverem um padrão razoável de dignidade para suas populações.

Desse modo, a aplicação em larga escala das recém revitalizadas ideias liberais Estado mínimo, redução de políticas de inclusão econômica e social, desregulamentação de setores da economia e das relações de trabalho etc. - juntamente com a abertura dos mercados mundiais e o progresso tecnológico, atuaram sem freios de contenção no sentido de reduzir a qualidade de vida da maioria da população. Em síntese, o crescimento econômico passou a causar a ruína do desenvolvimento humano.

Nesse contexto, os retrocessos provocados no âmbito do desenvolvimento humano afetam a solidez da democracia. E não poderia ser de outro modo já que a deterioração da qualidade de vida da população contraria o interesse da maioria dos cidadãos de qualquer país. Dentro do regime democrático, contudo, os achaques ao desenvolvimento humano desafiam até mesmo a lógica do sistema, que foi criado para viabilizar a supremacia do interesse público.

A democracia representativa, ferramenta moderna do desenvolvimento humano, transformou-se em obstáculo para o tipo de crescimento econômico que vem sendo implementado no mundo nas duas últimas décadas do século XX. Sem perder de vista as limitações de uma abordagem jurídica sobre um problema delineado na mesma proporção por fatores políticos, jurídicos e econômicos, o presente artigo tem por objetivo demonstrar que a compatibilização entre crescimento econômico e desenvolvimento humano mediante uma agenda contínua de concretização dos direitos sociais é imprescindível para a superação da crise da democracia. 


\section{METODOLOGIA}

A metodologia de abordagem é analítica, empírica e crítica. Parte da análise do problema apresentado pelo referencial teórico e empírico utilizado, desenvolvendo uma crítica argumentativa no sentido da conciliação de crescimento econômico e desenvolvimento humano para a superação da crise da democracia.

\section{DISCUSSÃO E RESULTADOS}

\subsection{Democracia representativa e o direito de voto}

A Constituição francesa de 1791, adotando a visão do abade Sieyès exposta em sua obra Que'st-ce que le Tiers État?, retirou o poder político (soberania) das mãos do monarca, mas não o entregou ao povo, atribuindo-o, isto sim, à nação, entidade abstrata incapaz de exercê-lo diretamente e suscetível, portanto, de servir à promoção de interesses não partilhados pela maioria da população (COMPARATO, 2014). Esse posicionamento, conveniente para os interesses da classe social que efetivamente chegara ao poder com a Revolução Francesa, serviu de alicerce para edificação da democracia moderna, que assumiu feição eminentemente indireta.

Em sentido contrário, Rousseau adverte que a soberania não pode ser mediada, pois é da índole do poder político ser expresso diretamente por seu titular, estatuindo como condição sine qua non à existência de uma verdadeira democracia a igualdade de condições sociais e econômicas (ROUSSEAU, 1973). Ainda que se atribua ao pensamento de Rousseau um sentido compatível com o sistema capitalista, atenuando-se o rigor dessa específica condição para que seja entendida como exigência de que todos os cidadãos tenham condições econômicas e sociais indispensáveis à preservação da dignidade humana, resta incontornável a lição vertida concomitantemente com a formação do Estado liberal acerca da incompatibilidade entre democracia e extrema desigualdade social e econômica.

Aliás, Rousseau baseou sua concepção de democracia na Antiguidade Clássica, visto que nas cidades-estado gregas, a coexistência do sufrágio popular direto com a manutenção de excessiva desigualdade econômica e social entre os cidadãos resultou no cometimento de crimes inomináveis determinados pela maioria privada de condições dignas de vida contra a 
minoria aquinhoada de bens, o que ensejou o caos econômico no qual soçobrou a democracia dos antigos (COULANGES, 2002).

Todavia, a democracia moderna nasceu representativa e indiferente à condição econômica e social dos cidadãos. Em que pese os inevitáveis prejuízos para a concretização do ideal democrático que decorrem da mediação entre o povo e o exercício do poder político, a dimensão geográfica dos Estados e a complexidade das relações sociais, econômicas e jurídicas na atualidade não permitem que se possa abolir a democracia representativa.

Entretanto, a impossibilidade de descarte da democracia representativa em nada afeta a utilização da lição de Rousseau no tocante à exigência de combate às desigualdades sociais e econômicas, visto que - assim como na democracia direta - o exercício indireto do poder político somente pode ser qualificado como democrático quando pressupõe a concretização de direitos sociais que assegurem o teor mínimo de liberdade ao cidadão. Não há que se falar em democracia sem liberdade substancial, a qual resulta da construção de um patamar mínimo civilizatório mediante a efetivação dos direitos sociais (POMPEU, 2005).

Dessarte, tanto na democracia direta, quanto na democracia indireta ou representativa, os contrastes profundos de situação econômica e social entre os cidadãos criam tensões econômicas, sociais e políticas impeditivas da efetivação e concomitantemente contrárias à preservação da democracia.

Por conseguinte, considerando que, no âmbito da democracia representativa, o vínculo entre Estados democráticos e regime democrático reside primordialmente no voto periódico e universal, ou seja, que a expressão por excelência do sufrágio popular na democracia representativa é o voto, torna-se inescapável concluir que esse instrumento consiste na expressão da liberdade de escolha do cidadão somente quando é satisfeito o pressuposto fático da garantia de um padrão mínimo de dignidade para os cidadãos mediante a efetivação de direitos sociais.

Realmente, sem a concretização dos direitos sociais esvazia-se a força do voto, retirase-lhe progressivamente a aptidão para dotar a democracia de representatividade, visto que por 'representativa' deve ser entendida a democracia na qual quem exerce o poder político 'representa o interesse da maioria dos cidadãos', sendo pressuposto da fidedignidade dessa representação a liberdade formal "e" material dos representados. 
Nesse sentido, o indivíduo que vive preocupado em satisfazer necessidade básicas como comer, abrigar-se etc. desumaniza-se a ponto de não poder desejar ou decidir politicamente (ARENDT, 2007). Não há liberdade para embasar qualquer escolha política abaixo de uma mínima proteção econômica e social, razão pela qual o cidadão destituído desse atributo apenas simula o exercício do direito de sufrágio.

Como se observa, a complementariedade entre liberdade e igualdade (RAWSL, 2008, p.247-252) exprime-se em todo seu vigor na Teoria da Democracia, visto que o sufrágio popular expresso por meio do voto é apenas um simulacro de si mesmo quando o cidadão não goza da liberdade substancial advinda da concretização dos direitos sociais, os assim denominados direitos de igualdade. O voto periódico e universal não possui - sem a garantia de um patamar mínimo de dignidade a todos os cidadãos - aptidão para dotar a democracia de representatividade, visto que nesse panorama o voto não conterá o teor de liberdade necessário ao desempenho de tamanha tarefa.

O voto está para a democracia como esta para o desenvolvimento humano, numa relação de interdependência em que todos os elementos da cadeia são negativamente atingidos quando não são efetivados os direitos sociais. Considerando que o tipo de crescimento econômico praticado desde o último quartel do século $\mathrm{XX}$ prejudicou sobremaneira o desenvolvimento humano ao impedir a concretização dos direitos sociais, mas que em nenhum dos países onde se manifesta a crise da democracia foi restringido o direito de voto tampouco canceladas ou abolidas eleições -, pode-se inferir que esse novo modelo de capitalismo não atua somente contra o desenvolvimento humano mas que age diretamente também neutralizando instrumentos e instituições democráticas, o que será abordado no próximo tópico.

\subsection{Capitalismo e democracia: a necessária conciliação entre crescimento econômico e} desenvolvimento humano.

Em razão da mitigação intencional e calculada de efeitos naturais do sistema capitalista, como a concentração de renda e precarização do trabalho, entre os anos de 1945 a 1975, disseminou-se a tese da compatibilidade espontânea entre capitalismo e democracia. Porém, a falsidade dessa ideia foi demonstrada por Thomas Piketty, o qual enfatiza que "não há nada de natural ou espontâneo" na redução da desigualdade verificada nas democracias 
ocidentais em razão das políticas públicas implementadas desde o fim da Segunda Grande Guerra até meados dos anos 1970, e tampouco no seu impacto positivo sobre o aprofundamento dessas mesmas democracias (PIKETTY, 2004, p.233-314).

Por conseguinte, em razão da desconstrução gradual dos mecanismos macroeconômicos que promoviam direitos sociais nos Estados democráticos, ou seja, devido à desarticulação entre crescimento econômico e desenvolvimento humano, o triunfo do capitalismo no mundo, ao invés de resultar num fortalecimento da democracia, produziu efeito diametralmente oposto.

Mas, apenas a mudança global de orientação macroeconômica não responde pela dimensão da crise da democracia representativa consoante ela se apresenta na atualidade. Houve um agravamento dessa crise nas últimas décadas que evidenciou o fato de que o crescimento econômico entrou em rota de colisão com o desenvolvimento humano, o que só foi possível mediante a neutralização da ferramenta mais eficaz para a construção do desenvolvimento humano: a democracia.

Para explicar a origem desse recrudescimento do embate entre capitalismo e democracia representativa, inicialmente remete-se ao magistério de Norberto Bobbio, que renovou a pergunta de Heródoto acerca da melhor forma de governo sustentando que, para formular um juízo sobre o tema, não é preciso que se leve em conta somente quantos e quais são os governantes, mas igualmente qual a sua forma de governar (BOBBIO, 2002).

Nesse diapasão, a dimensão do choque entre democracia representativa e capitalismo exige a formulação de um questionamento não somente sobre a forma de governar - via trilhada sem muito êxito até o presente momento -, mas sim que seja problematizado e analisado criticamente como se alcança o poder político dentro do novo modelo de capitalismo que vem desenvolvendo-se desde o final dos anos setenta do século XX.

Com efeito, a crise da democracia representativa não instalou-se apenas em razão da retirada dos mecanismos macroeconômicos que neutralizavam o conflito entre capitalismo e democracia. Esse é seu aspecto negativo, caracterizado pela inação. Do ponto de vista positivo, vale dizer, sob a ótica do agir, as transformações operadas no capitalismo a partir do último quartel do século passado induziram uma atuação do poder econômico sobre o poder político visando cooptá-lo para priorizar e satisfazer seus interesses. 
Nessa linha de pensamento, posto que o capitalismo atua por intermédio do poder econômico e que democracia, essencialmente, diz respeito a quem investe outrem no poder político e a quais os requisitos legítimos para essa investidura, verifica-se que o embate entre capitalismo e democracia, em sua vertente mais agressiva, coloca de um lado o poder econômico e de outro os mecanismos democráticos de acesso ao poder político.

Em outras palavras, a crise da democracia representativa é fomentada não somente pela omissão estatal em concretizar direitos sociais, em prover o desenvolvimento humano, mas igualmente pela atuação do poder econômico sobre os mecanismos de acesso ao poder político, de maneira a submeter esse poder para que ele sirva aos interesses do capital em detrimento dos interesses da população.

Nesse sentido, o agravamento da crise da democracia representativa teve como catalizador a conjugação entre globalização, desregulamentação econômica, progresso tecnológico e neoliberalismo desde o final da década de setenta do século passado - fenômeno que converteu o capitalismo democrático em supercapitalismo e que ocasionou o aumento desmedido da competição mundial entre as empresas pela conquista e manutenção de suas carteiras de consumidores e investidores (REICH, 2008).

Nessa ordem de ideias, o supercapitalismo provocou um aumento exponencial da competição entre as empresas, que passaram a alocar altas somas de dinheiro em financiamento político e, por via de consequência, a aparelhar as instituições democráticas para auxiliarem no cumprimento de suas metas de maximização de lucros e redução de custos.

Realmente, quando esgotaram-se as possibilidades de barateamento de custos e aumento de dividendos sem qualquer ingerência estatal, o supercapitalismo transferiu a arena das lutas empresariais para o setor público, que foi invadido por uma multidão de lobistas e, progressivamente, por lobistas detentores de mandatos eletivos, os quais transformaram as instituições democráticas em departamentos auxiliares das empresas financiadoras destinados ao cumprimento de metas de maximização de ativos e redução de passivos.

Eis porque, sob o pálio do supercapitalismo, apesar de haver eleições periódicas e sufrágio universal, o interesse público, notadamente aquele ligado à efetivação e preservação dos direitos sociais, não possui espaço nas agendas governamentais desses Estados "a que 
chamamos de democracia por inércia ou por não sabermos que outro nome lhe dar" (SANTOS, 2015, p. 14), o que gera a insatisfação da população com a incapacidade do sistema político de prover condições dignas de vida que, gradualmente, transforma-se em desilusão com a democracia representativa.

Em sentido semelhante, mesmo democracias sólidas e tradicionais assistem uma progressão exponencial do dispêndio de recursos em campanhas políticas. O poder econômico impõe seus interesses e corrompe a democracia representativa a tal ponto que, apesar de haver eleições periódicas e sufrágio universal, não há possibilidade de acesso ao poder político de representantes alinhados ao ideal de efetivação dos direitos sociais em número suficiente para garantir o êxito dessa meta.

Por via de consequência, a insatisfação da população com a incapacidade do sistema político de verberar seus interesses e prover condições dignas de vida transforma-se em descontentamento profundo com a democracia representativa, que embora não seja um fim em si mesma é uma ferramenta eficaz para viabilizar o desenvolvimento humano (SEN, 2010, p.193-209).

A democracia é instrumental com relação à conquista de direitos sociais, ou seja, ao desenvolvimento humano. Simultaneamente, o regime democrático depende da garantia do patamar mínimo de dignidade a todos os cidadãos decorrente do desenvolvimento humano para sua preservação. Em outras palavras, o desenvolvimento humano é a meta e o sustentáculo da democracia. Ela visa ao desenvolvimento humano e ao mesmo tempo mantém-se em razão desse desenvolvimento.

Ademais, o crescimento econômico não é incompatível com regramentos que visem impedir sua edificação ao custo do sacrifício do desenvolvimento humano. O conhecimento e a ação humana devem reger-se por princípios e valores éticos, pois, conforme o mito da criação descrito por Protágoras no diálogo de Platão que possui o mesmo nome, o progresso no conhecimento e nas técnicas empregadas pelo homem devem sempre vir acompanhados da observância de limites éticos por um imperativo da preservação do mais alto de todos os valores: a vida humana (COMPARATO, 2006, p. 35-37). Destarte, a democracia e o crescimento econômico são os dois pilares sobre os quais deve repousar o desenvolvimento humano. 
Por conseguinte, na medida em que a insatisfação da população com a incapacidade do sistema político de prover condições dignas de vida - por intermédio da efetivação de seus direitos sociais - transformou-se em descontentamento profundo com a democracia representativa, a compatibilização entre crescimento econômico e desenvolvimento humano tornou-se imprescindível pois nisso reside a chave para a superação da crise da democracia, cuja solução, por sua vez, tornará o desenvolvimento humano uma conquista definitiva.

\section{CONCLUSÃO}

A crise da democracia representativa no século XXI pode ser resumida mediante a seguinte asserção: o modelo de crescimento econômico imposto desde o último quartel do século passado causou prejuízos evidentes ao desenvolvimento humano e à democracia representativa. Portanto, verifica-se que compreender o processo de degradação simultânea da democracia representativa e da qualidade de vida dos cidadãos sob o pálio do supercapitalismo exige uma análise do sistema político e do sistema econômico como um todo integrado.

Assim, cumpre destacar que o fenômeno do supercapitalismo é muito mais que a simples adoção dos postulados do capitalismo liberal no âmbito de alguns Estados. Trata-se, isto sim, de uma tendência mundial do crescimento econômico resultante da conjugação entre globalização, desregulamentação econômica (abrangida nesse setor a desregulamentação das relações de trabalho), conquistas do progresso tecnológico que facilitaram as comunicações e reduziram postos de trabalho, e neoliberalismo.

Seguindo essa linha de raciocínio, constata-se que a crise da democracia tem suas raízes na simples imposição da agenda neoliberal às democracias a partir da segunda metade da década de setenta do século XX, mas o agravamento dessa crise teve como catalizador a substituição do capitalismo democrático pelo supercapitalismo, vertente do crescimento econômico destituída de vínculos com os valores éticos que subjaziam ao capitalismo democrático, o qual conciliava crescimento econômico com desenvolvimento humano.

A presente análise do supercapitalismo demonstra que a crise da democracia representativa possui um aspecto negativo, consistente na retirada dos mecanismos macroeconômicos que neutralizavam o conflito entre capitalismo e democracia. E outro positivo, consistente na atuação do poder econômico sobre o poder político visando cooptá-lo 
para priorizar e satisfazer seus interesses. No âmbito da atuação do poder econômico sobre os instrumentos e instituições da democracia representativa, importa destacar a necessidade de entender de que maneira o supercapitalismo aparelha a democracia à fim de que se possa criar ferramentas para proteger o sistema democrático e, assim, viabilizar a harmonização entre crescimento econômico e desenvolvimento humano no século XXI.

Nessa lógica, a solução da crise da democracia representativa perpassa o desafio de redirecionar a agenda estatal no sentido da implementação de políticas de redução da concentração de renda e das desigualdades econômicas, mas igualmente implica em estudar o fenômeno do supercapitalismo e seu impacto sobre a democracia representativa para que se possa elaborar propostas de mudança nos mecanismos jurídicos de delegação e aquisição do poder político capazes de restaurar o vigor da democracia representativa. Em razão da inelutável integração econômica mundial e do caráter global do problema, a longo prazo a solução definitiva passa pela criação de instrumentos de pacíficos de governança global.

\section{REFERÊECIAS}

ARENDT, Hannah. A condição humana. Tradução de Roberto Raposo. 10 ed. Rio de Janeiro: Forense Universitária, 2007.

AMARAL, Gustavo. Direito, escassez e escolha: em busca de critérios jurídicos para lidar com a escassez de recursos e as escolhas trágicas. Rio de Janeiro: Renovar, 2001.

APEL, Karl-Otto. Transformação da filosofia I. Tradução de Paulo Astor Soethe. São Paulo: Edições Loyola, 2000.

BARRETO, José Anchieta Esmeraldo; MOREIRA, Rui Verlaine de Oliveira. Ensaio sobre a incerteza. Nomos. Fortaleza, v. 22, n.1/2, p. 171-192, jan.-dez./2003.

. (Org.). Imaginando erros. Fortaleza: UFC - Casa de José de Alencar Programa Editorial, 1997, p. 115-145.

; O problema da indução: o cisne negro existe. Fortaleza: edição dos autores, 1993. 
BARROSO, Luís Roberto. O direito constitucional e a efetividade de suas normas. 8. ed. Rio de Janeiro: Renovar, 2006.

BERCOVICI, Gilberto. A problemática da constituição dirigente: algumas considerações sobre o caso brasileiro. Revista de Informação Legislativa. v. 1. n. 142, p. 33-49, abr.jun./1999.

BIELEFELDT, Heiner. Filosofia dos direitos humanos. Tradução de Dankwart Bernsmüller. São Leopoldo: Unisinos, 2000.

BOBBIO, Norberto. Liberalismo e democracia. Tradução de Marco Aurélio Nogueira. São Paulo: Brasiliense, 2013.

O futuro da democracia. Tradução de Marco Aurélio Nogueira. 8. ed. São Paulo: Paz e Terra, 2002.

Estado, governo e sociedade. Tradução de Marco Aurélio Nogueira. 13 ed. São Paulo: Paz e Terra, 2007.

Quais as alternativas para a democracia representativa. In BOBBIO, Norberto, et al. O Marxismo e o Estado. Tradução Federica L. Boccardo e Renée Lerie. Rio de Janeiro: Graal, 1979.

A era dos direitos. Tradução de Carlos Nelson Coutinho. Rio de Janeiro: Campus, 2004.

BUCCI, Maria Paula Dallari. Direito administrativo e políticas públicas. 2 tiragem. São Paulo: Saraiva, 2006.

CANARIS, Claus-Wilhelm. Pensamento sistemático e conceito de sistema na ciência do direito. Tradução de Antônio Menezes Cordeiro. 3. ed.. Lisboa: Fundação Calouste Gulbenkian, 2002.

CENCI, Elvi Miguel. A reflexão ética de Karl-Otto Apel. In: CARVALHO, José Maurício de (Org.). Problemas e teorias da ética contemporânea. Porto Alegre: EDIPUCRS, 2004, p. 335336. 
COMPARATO, Fábio Konder. A civilização capitalista. 2ed. São Paulo: Saraiva, 2014. Ética: Direito, Moral e Religião no mundo moderno. São

Paulo: Companhia das Letras, 2006.

COSTA, Regenaldo. Ética do discurso e da verdade em Apel. Belo Horizonte: Del Rey, 2002.

COULANGES, Fustel. A cidade antiga. Tradução de Jean Melville. São Paulo: Martin Claret, 2002.

DWORKIN, Ronald. Levando os direitos a sério. Tradução de Nelson Boeira. São Paulo: Martins Fontes, 2002.

O império do direito. Tradução de Jefferson Luiz Camargo. São Paulo: Martins Fontes, 2003.

DAHL, Robert A. Sobre a Democracia. Tradução de Beatriz Sidou. Brasília: Universidade de Brasília, 2001.

On political equality. New Haven \& London: Yale University Press, 2006.

FRIEDRICH, Müller. Quem é o povo? A questão fundamental da democracia. Tradução de Peter Naumann, revisão Paulo Bonavides. 3 ed. São Paulo: Max Limonad, 2003.

Que grau de exclusão ainda pode ser tolerado por um sistema democrático? Revista da Procuradoria Geral do Município de Porto Alegre. Tradução de Peter Naumann. Porto Alegre: Unidade Editorial da Secretaria de Cultura, out/ 2000.

GADAMER, Hans-Georg. Verdade e método. Vol. I. Tradução de: Flávio Paulo Meurer. Petrópolis: Vozes, 1997, 2v.

GALDINO, Flávio. Introdução à teoria dos custos dos direitos: direitos não nascem em árvores. Rio de Janeiro: Lumen Juris, 2005. 
GARCÍA DE ENTERRÍA, Eduardo. Revolucíon francesa y administración contemporânea. 4. ed. Madrid: Civitas, 1994.

GARCIA, Emerson (Coord.). A efetividade dos direitos sociais. Rio de Janeiro: Lumen Júris, 2004.

GRAU, Eros Roberto. A ordem econômica na constituição de 1988: interpretação e crítica. 11. ed. São Paulo: Malheiros, 2006.

HABERMAS, Jüngen. Direito e democracia: entre facticidade e validade. Vol. I. Tradução de Flávio Beno Siebeneichler. Rio de Janeiro: Tempo Brasileiro, 1997.

O discurso filosófico da modernidade. Tradução de Luiz Sérgio Repa e Rodnei Nascimento. São Paulo: Martins Fontes, 2000.

HOLMES, Stephen; SUNSTEIN, Cass. The cost of rights: why liberty depends on taxes. Nem York: W.W. Norton and Company, 1999.

JELLINEK, Georg. Teoría general del estado. Buenos Aires: Editorial Albatroz, 1973.

LIJPHART, Arend. Las democracias contemporâneas: un estudio comparativo. Traduccion de Elena de Grau. 4 ed. Barcelona: Editora Ariel, 1999.

LOPES, José Reinaldo de Lima. Direito subjetivo e direitos sociais: o dilema do judiciário no estado social de direito. In: FARIA, José Eduardo (Org.). Direitos humanos, direitos sociais e justiça. São Paulo: Malheiros, 2005. p. 68-93.

LINZ, Juan J. La quiebra de las democracias. Traduccion de Rocio de Teran. Buenos Aires: Alianza Editorial, 1991.

MCCARTHY, Thomas. La teoria critica de Jüngen Habermas. Tradução de M. Jimenez. Madrid: Tecnos, 1987.

MELLO, Cláudio Ari. Os direitos sociais e a teoria discursiva do direito. Revista de Direito Administrativo, Rio de Janeiro, v. 1, n. 224, p. 239-284, abril-junho/2001. 
PIKETTY, Thomas. O capital no século XXI. Tradução de Monica Baumgarten de Boile. Rio de Janeiro: Intrínseca, 2014.

PORT, Otávio Henrique Martins. Os direitos sociais e econômicos e a discricionariedade da administração pública. São Paulo: RCS, 2005.

POMPEU, Gina Vidal Marcílio. Liberdade e igualdade: condicionamentos democráticos para o desenvolvimento humano, para o crescimento econômico e à estabilidade social. In: CARDUCCI, Michele; POMPEU, Gina Marcilio; SANCHEZ, Miguel Revenga (Orgs.) Direito constitucional nas relações econômicas: entre o crescimento econômico e o desenvolvimento humano. Rio de Janeiro: Lumen Juris, 2014.

Direito à educação: controle social e exigibilidade judicial. Rio de Janeiro - São Paulo - Fortaleza: ABC Editora, 2005.

QUEIRÓZ, Cristina M. M.. Os actos políticos no estado de direito: o problema do controle jurídico do poder. Coimbra: Almedina, 1990.

RAWLS, John. Justiça e democracia. Tradução de Irene A. Paternot. São Paulo: Martins Fontes, 2002.

O liberalismo político. Tradução de Álvaro de Vita. São Paulo: Editora WMF Martins Fontes, 2016.

. Uma teoria da justiça. Tradução de Jussara Simões. 3 ed. São Paulo: Martins Fontes, 2008.

REICH, Robert B. O supercapitalismo: como o capitalismo tem transformado os negócios, a democracia e o cotidiano. Tradução de Afonso Celso da Cunha Serra. Rio de Janeiro: Elsevier, 2008.

ROUSSEAU, Jean-Jacques. Do Contrato Social ou Princípios do Direito político. Coleção Os Pensadores. Tradução de Lourdes Santos Machado. São Paulo: Editora Abril, 1973. 
SANTOS, Boaventura de Sousa. O Direito dos Oprimidos: sociologia crítica do Direito. São Paulo: Cortez, 2014.

SARTORI, Giovanni. Democracia: cosa é. Milano: RCS Libri S.p.A., 2000.

SEN, Amartya. Desenvolvimento como liberdade. Tradução de Laura Teixeira Mota. São Paulo: Companhia das Letras, 2010.

ZAGREBELSKY, Gustavo. A crucificação e a democracia. Tradução de Monica de Sanctis Viana. São Paulo: Saraiva, 2011. 